\title{
A PROTEÇÃO DOS DIREITOS INTELECTUAIS COLETIVOS ASSOCIADOS AOS POVOS E COMUNIDADES TRADICIONAIS BRASILEIROS POR INTERMÉDIO DE UM SISTEMA JURÍDICO SUI GENERIS: AJUSTES E DESAFIOS
}

\section{THE PROTECTION OF COLLECTIVE INTELLECTUAL RIGHTS ASSOCIATED WITH THE BRAZILIAN TRADITIONAL PEOPLES AND COMMUNITIES THROUGH INTERMERCE OF A SUI GENERIS LEGAL SYSTEM: ADJUSTMENTS AND CHALLENGES}

Beatriz Cobbo de Lara'

Alessandra Galli Aprá

\section{RESUMO}

Tendo em vista a complexidade atinente aos conhecimentos tradicionais associados, o presente estudo pretende apresentar uma reflexão jurídica crítica sobre o assunto. Para tanto, em um primeiro momento são abordados os conhecimentos tradicionais associados sob a perspectiva dos Direitos Humanos Fundamentais, contextualizados pela relevância do princípio do direito ao consentimento livre, prévio e informado. Em seguida são analisados os conhecimentos tradicionais associados sob aspectos culturais, partindo-se do ponto de vista da atual situação normativa do tema no Brasil. Por fim, pretende-se demonstrar a necessidade da construção de um sistema jurídico sui generis sobre os conhecimentos tradicionais associados que proteja de fato os direitos intelectuais coletivos desses grupos de pessoas. A metodologia empregada foi a descritiva do tipo mista - quantitativa e qualitativa - voltada para a apreciação documental, assim como para análises sistemáticas da doutrina, das normas e da

\footnotetext{
${ }^{1}$ Mestranda em Direitos Fundamentais e Democracia pelo Centro Universitário Unibrasil (2018/2020). Especialista em Direito Civil pela LFG. Especialista em Direito Público pela Escola da Magistratura Federal do Paraná (ESMAFE). Especialista em Direito Aplicado pela Escola da Magistratura do Paraná (EMAP). Especialista em Direito Tributário pela Universidade Positivo (UP). Especialista em Diplomacia e Relações internacionais pelo Centro Universitário Curitiba (UNICURITIBA). Advogada. E-mail: beatrizde.lara@hotmail.com. ORCID ID https://orcid.org/0000-0001-9108-7698

${ }^{2}$ Doutora em Tecnologia e Desenvolvimento pela Universidade Tecnológica Federal do Paraná (UTFPR); Mestre em Direito Econômico e Social - linha de pesquisa de Direitos Socioambientais - e Especialista em Direito Socioambiental, ambos pela Pontifícia Universidade Católica do Paraná (PUC/PR). Professora do Centro Universitário Curitiba (UNICURITIBA), da Escola da Magistratura do Paraná (EMAP) e da Escola Superior de Advocacia do Paraná (ESA/PR). Secretária da Comissão de Direito Ambiental da OAB/PR para o triênio 2019-2021. Advogada. E-mail: professoragalli@gmail.com. ORCID ID https://orcid.org/0000-0002-9914-3989
} 
jurisprudência no âmbito da realidade dos conhecimentos tradicionais associados (CTAs) no Brasil.

Palavras-chave: Conhecimentos tradicionais associados. Direitos culturais. Direitos Humanos Fundamentais. Direitos intelectuais.

\begin{abstract}
In view of the complexity associated with traditional knowledge associated with it, the present study intends to present a critical legal reflection on the subject. In order to do so, the associated traditional knowledge is approached from the perspective of fundamental human rights, contextualized by the relevance of the principle of the right to free, prior and informed consent. Next, the traditional knowledge associated with cultural aspects is analyzed, starting from the point of view of the current normative situation of the subject in Brazil. Finally, it is intended to demonstrate the need to build a sui generis legal system on associated traditional knowledge that effectively protects the collective intellectual rights of these groups of people. The methodology used was descriptive of the mixed - quantitative and qualitative type - focused on documentary appreciation, as well as for systematic analyzes of doctrine, norms and jurisprudence within the scope of the traditional associated knowledge (CTAs) in Brazil.
\end{abstract}

Keywords: Associated traditional knowledge. Cultural rights. Fundamental Human Rights. Intellectual rights.

\title{
1 INTRODUÇÃO
}

Tendo em vista a complexidade e os problemas atinentes aos conhecimentos associados aos Povos e Comunidades Tradicionais, o presente estudo pretende evidenciar que a construção de normas, planos e programas sobre o assunto pode ser inviável sem a abertura à participação no processo de decisão daqueles que provavelmente devam ser os maiores interessados no assunto, os Povos e Comunidades Tradicionais, independente de quais sejam os grupos que os conformam. Neste contexto, o artigo tem sua linha fundamental de desenvolvimento calcada na análise normativa, doutrinária, jurisprudencial e de casos que envolvem o tema e que não chegaram a ser judicializados.

A Seção 2 destina-se à abordagem dos conhecimentos tradicionais associados (CTAs) considerados como Direitos Humanos. Na Seção 3, por sua vez, analisa-se a Lei n. $\cong$ 13.123/2015, conhecida como Lei de Biodiversidade, e intenta ponderar a 
necessidade de ajustes e desafios que a proteção de tais conhecimentos tradicionais associados (CTAs) atualmente enfrenta. Por fim, na Seção 4 se abordará a necessidade da construção de um sistema jurídico sui generis a fim de tutelar os conhecimentos tradicionais associados (CTAs) como forma de proteger efetivamente essas comunidades e seus respectivos saberes, rendendo-Ihes dividendos.

\section{2) O CONHECIMENTO TRADICIONAL ASSOCIADO E OS DIREITOS HUMANOS}

De início insta destacar que o inciso I do artigo $3^{\circ}$ do Decreto Federal $n . .6 .040$, de 07 de fevereiro de 2007 define "Povos e Comunidades Tradicionais" como sendo:

grupos culturalmente diferenciados e que se reconhecem como tais, que possuem formas próprias de organização social, que ocupam e usam territórios e recursos naturais como condição para sua reprodução cultural, social, religiosa, ancestral e econômica, utilizando conhecimentos, inovações e práticas gerados e transmitidos pela tradição (BRASIL, 2007).

O Decreto n. .8 .750 , de 9 de maio de 2016, por sua vez, ao instituir o Conselho Nacional dos Povos e Comunidades Tradicionais, no parágrafo 2o do seu artigo 4ํㅜㄴ elenca um rol de segmentos da sociedade civil que devem ser representados neste Conselho - por intermédio de um titular e dois suplentes - e, assim, acaba por listar quais grupos de pessoas são consideradas Povos e Comunidades Tradicionais no Brasil. São eles:

I - povos indígenas;

II - comunidades quilombolas;

III - povos e comunidades de terreiro/povos e comunidades de matriz africana;

IV - povos ciganos;

$\mathrm{V}$ - pescadores artesanais;

$\mathrm{VI}$ - extrativistas;

VII - extrativistas costeiros e marinhos;

VIII - caiçaras;

IX - faxinalenses;

$X$ - benzedeiros;

XI - ilhéus;

XII - raizeiros;

XIII - geraizeiros;

XIV - caatingueiros;

XV - vazanteiros; 


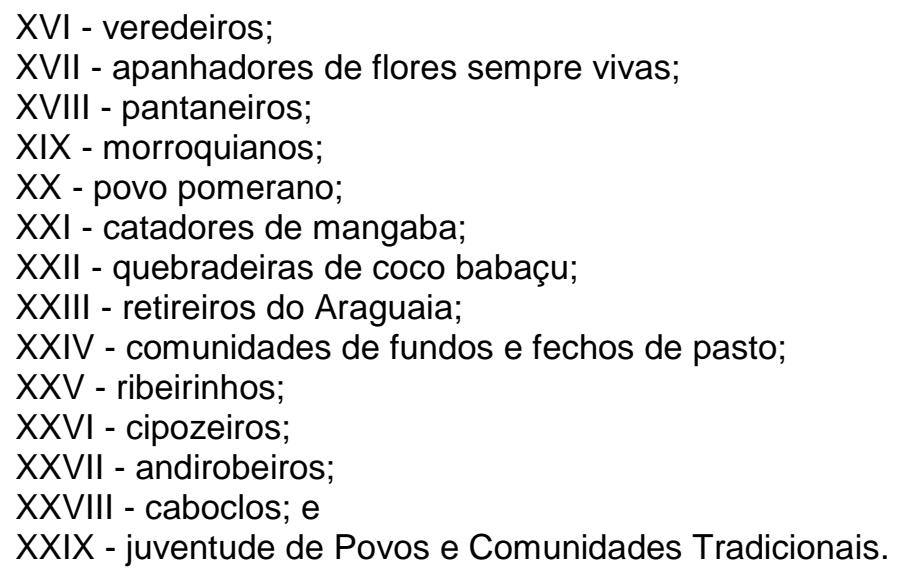

Faz-se a citação literal destes 29 grupos de pessoas propositalmente com a intenção de destacar um contingente de brasileiros das mais diversas origens, cujas características próprias de organização social, uso dos territórios e dos recursos naturais os diferenciam e deveriam Ihes render respeito e atenção por parte do Estado Brasileiro.

Neste estudo optou-se por referir-se a tais grupos de pessoas não de maneira individualizada, pormenorizada nas especificidades e peculiaridades de cada qual, mas tão somente como "Povos e Comunidades Tradicionais", os quais são conformados por indivíduos que comungam entre si de conhecimentos que merecem ser valorizados.

Partindo-se destas premissas básicas passa-se a analisar a importância conferida aos recursos biológicos disponíveis nos territórios dos Povos e Comunidades Tradicionais enquanto elementos indispensáveis não apenas para a reprodução cultural, social, religiosa, ancestral e econômica destes grupos humanos, mas também como os usos derivados dos conhecimentos tradicionalmente associados a estes recursos biológicos deveriam gerar riquezas para tais povos e comunidades.

Segundo a Convenção sobre a Diversidade Biológica (CDB), ratificada pelo Brasil em 1998, por intermédio do Decreto n.․ 2.519, recursos biológicos compreendem "recursos genéticos, organismos ou partes destes, populações, ou qualquer outro componente biótico de ecossistemas, de real ou potencial utilidade ou valor para a humanidade" (BRASIL, 1998). Assim, os Povos e Comunidades Tradicionais são populações que dispõem em seus territórios de recursos biológicos que devem ser 
protegidos por seu potencial valor para estas comunidades e também para toda a humanidade.

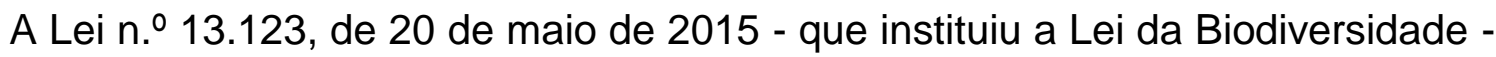
, ao definir o que vem a ser conhecimento tradicional associado citou especificamente alguns povos a este relacionados, o que não significa que tal conceito não possa ser aplicado aos demais grupos anteriormente referendados.

Assim, para o artigo $2^{\circ}$ da Lei da Biodiversidade, conhecimento tradicional associado refere-se à "informação ou prática de população indígena, comunidade tradicional ou agricultor tradicional sobre as propriedades ou usos diretos ou indiretos associadas ao patrimônio genético" (BRASIL, 2015). Ou seja, o conhecimento associado aos Povos e Comunidades Tradicionais, ou simplesmente Conhecimento Tradicional Associado (CTA) está intimamente relacionado ao contato direto e umbilical de tais povos e comunidades com a natureza e os usos diretos ou indiretos que estes fazem dela. Neste sentido, para Cristiane Derani (2002, p. 155),

\begin{abstract}
"o conhecimento tradicional associado é conhecimento da natureza, oriundo da contraposição sujeito-objeto sem a mediação de instrumentos de medida e substâncias isoladas traduzidas em códigos e fórmulas. É oriundo da vivência e da experiência, construído num tempo que não é aceito pela máquina da eficiência e da propriedade privada, mas cujos resultados podem vir a ser traduzidos em mercadoria geradora de grandes lucros, quando tomados como recursos da produção mercantil" (DERANI, apud DANTAS, 2006, p. 84).
\end{abstract}

A percepção do tempo para os povos e Populações Tradicionais não é o mesmo daquele observado freneticamente pelos moradores das cidades especialmente as grandes, mas não só elas - que, em grande parte, vivem em uma espiral insana e ansiosa atrás da concorrência, de competência, de produtividade, do consumo e do hiperindividualismo.

O tempo para os Povos e Populações Tradicionais está intimamente relacionado ao coletivo e seu transcurso ocorre respeitando-se os conhecimentos acerca das marés, dos ventos, das fases da lua, do desenrolar da vida das distintas espécies animais e vegetais com as quais comungam o mundo - conhecimentos estes que são passados de pais para filhos, especialmente por intermédio da oralidade e do respeito aos antepassados e a tudo o que eles representam. 
Importa destacar o que ensina Vladimir Garcia Magalhães (2001, p. 113), ao dispor acerca de propriedade intelectual, de biodiversidade e de biotecnologia, que o conhecimento associado aos Povos e Comunidades Tradicionais deve ser considerado "patrimônio cultural brasileiro", conforme os ditames do artigo $8^{\circ}, \S^{\circ}$, da Lei de Biodiversidade.

Neste mesmo sentido, segundo o Pacto Internacional sobre Direitos Civis e Políticos, adotado pela Assembleia Geral das Nações Unidas e ratificado no Brasil por intermédio do Decreto n. 592 , de 6 de julho de 1992, direitos culturais também são considerados direitos humanos:

Parte I. Artigo 1. Todos os povos têm direito à autodeterminação. Em virtude desse direito, determinam livremente seu estatuto político e asseguram livremente seu desenvolvimento econômico, social e cultural.

2. Para a consecução de seus objetivos, todos os povos podem dispor livremente de suas riquezas e de seus recursos naturais, sem prejuízo das obrigações decorrentes da cooperação econômica internacional, baseada no princípio do proveito mútuo, e do Direito Internacional. Em caso algum, poderá um povo ser privado de seus meios de subsistência.

(...)

Parte II. Artigo 5. 2. Não se admitirá qualquer restrição ou suspensão dos direitos humanos fundamentais reconhecidos ou vigentes em qualquer Estado Parte do presente Pacto em virtude de leis, convenções, regulamentos ou costumes, sob pretexto de que o presente Pacto não os reconheça ou os reconheça em menor grau (BRASIL, 1992).

Quando os conhecimentos relativos aos elementos bióticos e abióticos dos Povos e Comunidades Tradicionais são usurpados de certa forma se está diante de privação da subsistência destes povos e, pode-se afirmar que se está diante de biopirataria, ou seja, "atividade ilegal ou criminosa relacionada com os recursos biológicos" (DICIONÁRIO PRIBERAM, 2019).

Nesse contexto, o princípio do "consentimento livre, prévio e informado" funciona como pedra angular às regras de preservação cultural e do combate à biopirataria. Segundo a concepção de Melanie Nakagawao, o consentimento livre, prévio e informado é uma "ideia em desenvolvimento que incorpora um número crescente de acordos multilaterais sobre o meio ambiente", entre os quais destaca-se a 
Convenção sobre Diversidade Biológica, que concebe um regime de acesso e repartição de benefícios a partir dos Governos nacionais e das comunidades locais. (GRABNER, 2015, p. 25).

O consentimento livre, prévio e informado implica dizer que Povos e Comunidades Tradicionais possuem autodeterminação em relação ao patrimônio biológico que lhes pertence, a sua própria cultura, aos seus "modos de criar, fazer e viver" definidos como integrantes do patrimônio cultural brasileiro pelo artigo 216 da Constituição da República Federativa do Brasil de 1988 (BRASIL, 1988), enfim, ao modo como pretendem se desenvolver.

Por isto, Povos e Comunidades Tradicionais devem sempre ser consultados em relação a tudo o que lhes diz respeito, inclusive e especialmente no que tange ao uso comercial ou não atrelado direta ou indiretamente aos seus conhecimentos tradicionais associados (CTAs).

Nesta toada a Declaração sobre os Direitos dos Povos Indígenas reconheceu em seu preâmbulo a importância dos povos indígenas terem o "controle dos acontecimentos que os afetam"3. No mesmo sentido, a Convenção sobre Diversidade Biológica (CDB) em seus artigos 80, "j", 15, e 19 e a Convenção ‥ 169 da OIT - em seu artigo 6을 (GRABNER, 2015, p. 16-17), apontaram esse direito como essencial à proteção dos direitos humanos.

Essa é a tendência normativa-jurisprudencial. Tanto é assim que, recentemente, no caso Comunidad Saramaka vs. Suriname, em que houve a concessão de uso das terras tradicionais sem que o Estado promovesse a necessária e prévia informação às comunidades, em sentença de 28 de novembro de 2007 - Série $C$ ํo. 172, parágrafo 121 -, a Corte Interamericana de Direitos Humanos considerou que os povos tribais e indígenas possuem o direito "de serem titulares dos recursos naturais que utilizaram tradicionalmente dentro de seu território pelas mesmas razões pelas quais têm o direito de serem titulares da terra que usaram e ocuparam durante séculos".

\footnotetext{
3 “(...) O controle, pelos povos indígenas, dos acontecimentos que os afetam e as suas terras, territórios e recursos Ihes permitirá manter e reforçar suas instituições, culturas e tradições e promover seu desenvolvimento de acordo com suas aspirações e necessidades". Declaração das Nações Unidas sobre os Direitos dos Povos Indígenas. Publicada em: Rio de Janeiro, mar. 2008. Disponível em: <http://www.un.org/esa/socdev/unpfii/documents/DRIPS pt.pdf>. Acesso em 10 abr. 2019.
} 
Tal decisão é importante, na medida em que, "do contrário, a sobrevivência econômica, social e cultural destes povos est[aria] em risco" (CORTE apud BIJOS, 2016, p. 7898).

Embora haja uma espécie de "vácuo" legislativo no que se refere à definição acerca do princípio do "consentimento livre, prévio e informado", hoje o referido princípio funciona como um "direito fundamental e uma garantia de efetividade dos demais direitos reconhecidos aos povos indígenas e outras comunidades tradicionais, no âmbito dos direitos humanos, tanto no plano global e regional quanto no plano local ou nacional" (GRABNER, 2015, p. 25).

Isso porque, o pluralismo participativo - no que se refere à elaboração de normas, de políticas públicas, de planos e programas atinentes àqueles povos configura instrumento que aproxima o plano teórico da realidade e que, consequentemente, reforça a legalidade das decisões nessa área. Aliás, para Boaventura de Souza Santos e João Arriscado Nunes,

multiculturalismo, justiça multicultural, direitos coletivos, cidadanias plurais são hoje alguns dos termos que procuram jogar com as tensões entre a diferença e a igualdade, entre a exigência de reconhecimento da diferença e de redistribuição que permita a realização da igualdade (SANTOS; NUNES, 2003, p. 25).

Nesse passo, o direito ao "consentimento livre, prévio e informado" não deve limitar-se à simples consulta no processo de decisão sobre conhecimentos tradicionais associados (CTAs), pois representa hoje, a maior garantia na realização de um diálogo intercultural entre os povos tradicionais e outros atores da sociedade nacional e internacional (SANTOS; NUNES, 2003, p. 46).

2) A PROTEÇÃO DOS CONHECIMENTOS TRADICIONAIS ASSOCIADOS E A LEI DA BIODIVERSIDADE (LEI N. 13.123 /2015)

A edição da Lei n. 13.123 de 2015 - Lei da Biodiversidade - regulamentou 0 inciso II do $\S^{1^{\circ}}$ e $\circ \S^{4^{\circ}}$ do art. 225 da Constituição da República Federativa do Brasil de 
1988; bem como os artigos $1^{\circ}$, a alínea "j" do artigo $8^{\circ}$, a alínea "c" do artigo 10, o artigo 15 e os $\S 3^{\circ}$ e $4^{\circ}$ do artigo 16 da Convenção sobre Diversidade Biológica. Estes dispositivos tratam dos seguintes aspectos respectivamente: preservação da diversidade e integridade do patrimônio genético do País; utilização sustentável de componentes da diversidade biológica; acesso a recursos genéticos e acesso à tecnologia e transferência de tecnologia.

Tal Lei dispõe ainda sobre o acesso ao patrimônio genético, sobre a proteção e o acesso ao conhecimento tradicional associado e sobre a repartição de benefícios para a conservação e o uso sustentável da biodiversidade, além de revogar a Medida Provisória n.. 2.186-16, de 23 de agosto de 2001 (BRASIL, 2015).

Aparentemente, o pretexto da referida normatização foi humanitarista, benevolente e altruísta para com os Povos e Comunidades Tradicionais do país e também em relação ao meio ambiente. Diz-se aparentemente, porque da análise pormenorizada do seu conteúdo deduz-se que alguns dispositivos destoaram claramente do teor dos tratados internacionais dos quais o Brasil faz parte e, da própria Constituição da República Federativa do Brasil de 1988. Compulsando a Lei da Biodiversidade vê-se que alguns de seus dispositivos colocam em cheque a legalidade de toda a norma, tanto da perspectiva do controle de convencionalidade quanto sob a ótica do controle de constitucionalidade ${ }^{4}$.

Isso porque ao estabelecer a diferenciação entre conhecimentos tradicionais associados (CTAs) de origens identificáveis e conhecimentos tradicionais associados (CTAs) de origens não identificáveis ${ }^{5}$, a Lei da Biodiversidade, em alguns dispositivos,

\footnotetext{
${ }^{4} \mathrm{O}$ controle de constitucionalidade é, em linhas gerais, o controle do conteúdo formal (vigente) e material (validade) das normas inferiores em relação às normas superiors, ou seja, no âmbito interno, das normas infraconstitucionais em relação às normas constitucionais. Esse controle pode se dar de maneira difusa ou concentrada. $O$ controle difuso ocorre quando os Tribunais Superiores pátrios, podem, desde logo, compatibilizar o texto infraconstitucional com a Constituição Federal. O controle concentrado ocorre quando o controle concentrase em um único tribunal. O controle de convencionalidade é, em suma, uma adaptação do modelo de controle de constitucionalidade. É o controle do conteúdo formal (vigente) e material (validade) das normas internas nacionais - em relação ao conteúdo dos Tratados Internacionais ratificados pelo país. Da mesma forma, pode se dar via sistema difuso ou concentrado, a depender do tema abordado pelo Tratado (de acorco com o que preceitua o artigo 5ㅇ, parágrafo 3ㅇ da Constituição da República Federativa do Brasil de 1988 - Emenda Constitucional 45 de 2004).

5 "Este último sendo definido como aquele em que não há a possibilidade de vincular a sua origem a, pelo menos, uma população indígena, comunidade ou agricultor tradicional. Essa distinção visa solucionar questões em relação ao compartilhamento de conhecimentos e repartição de benefícios,
} 
desprotegeu o direito desses povos e comunidades tradicionais. Neste cenário, para melhor compreensão do assunto, passa-se a analisar os dispositivos da Lei de Biodiversidade com mais acurácia.

No primeiro caso, dos CTAs indentificáveis, se não houver exploração econômica do conhecimento associado aos povos e comunidades tradicionais o usuário - ou seja, aquele que pretende fazer uso de tal conhecimento -, submete-se apenas ao consetimento prévio e informado da comunidade - conforme dispõe o artigo 10 e, nesse caso, deve haver prova do consentimento - conforme o artigo 9‥

No caso de exploração econômica do conhecimento tradicional associado o Conselho de Gestão do Patrimônio Genético (CGEN) deve ser notificado do produto pronto ou do material reprodutivo - de acordo com o artigo 16, inciso I, sendo que o acordo de repartição de benefícios deve ser sempre prévio à exploração do produto ou material reprodutivo - de acordo com o artigo 16, inciso II - e o usuário deve depositar a metade do valor devido ao titular primário do CTA, no Fundo Nacional para a Repartição de Benefícios (FNRB).

Isso porque, a lei presume que todo conhecimento associado aos povos e comunidades tradicionais é partilhado por mais de uma comunidade que compartilhe das manifestações e usos das mesmas práticas - como elucidam os artigos 24 , §5ํe $25, \S 1^{\circ}$.

No segundo caso, daqueles conhecimentos tradicionais que não podem ser identificáveis e relacionados a um povo ou comunidade tradicional, os chamados CTAs não-identificáveis, o acesso a eles independe de consentimento prévio informado - de acordo com o que dispõe o artigo 9 , §2 - até porque não seria possível saber de quem se tomaria tal consentimento. Se não houver exploração econômica do conhecimento tradicional associado, o usuário não precisa celebrar acordo de repartição de benefícios ou fazer depósito no Fundo Nacional para a Repartição de Benefícios (FNRB). Porém, no caso de exploração econômica dos conhecimentos associados aos povos e comunidades tradicionais que não sejam identificáveis o usuário deverá, ou celebrar acordo de repartição dos benefícios advindos por tal exploração com a União, ou quando não é possível identificar todos os usuários de determinado conhecimento (SANTILLI, 2015, p. 38)". 
depositar no Fundo Nacional para a Repartição de Benefícios (FNRB) a quantia definida no artigo 23 da Lei de Biodiversidade ${ }^{6}$.

O usuário dos conhecimentos associados aos povos e comunidades tradicionais possui 365 dias, a partir da notificação do produto acabado ou do material reprodutivo para apresentar o acordo de repartição de benefício ao Conselho de Gestão do Patrimônio Genético (CGEN) - como preceitua o artigo 16 , §2" "ressalvados os casos que envolverem conhecimentos tradicionais associados de origem identificável" (BRASIL, 2015); sendo que "desde a notificação o usuário já pode explorar economicamente o produto oriundo dos recursos genéticos" (COSTA, 2017, p. 80).

Primeiramente, é de se notar que essa diferença entre conhecimentos tradicionais indentificáveis e não-identificáveis não encontra respaldo em nenhum tratado internacional. É criação jurídica genuinamente brasileira (COSTA, 2017, p. 47). Nesse passo, as críticas despontam no sentido de que a expressão "não-indentificável", proposta pela Lei da Biodiversidade, abre possibilidades para interpretações distintas, interpretações que fogem à razão pela qual a Lei foi editada - por exemplo, no sentido de que aquele que explora os recursos naturais e biológicos atrelados aos conhecimentos dos povos e populações tradicionais não "faça questão" de efetivamente realizar tal identificação, gerando prejuízos econômicos a tais povos e comunidades.

Assim, a expressão CTAs "não-indentificáveis" pode ser confundida com o conceito de domínio público ${ }^{7}$; pode dar brecha à empresa de biotecnologia que com base em alegações falaciosas, como por exemplo, diante da dificuldade na determinação da origem do saber, "não queira comprovar o consentimento livre, prévio

\footnotetext{
6 “Art. 20. Quando a modalidade escolhida for a repartição de benefícios monetária decorrente da exploração econômica de produto acabado ou de material reprodutivo oriundo de acesso ao patrimônio genético, será devida uma parcela de $1 \%$ (um por cento) da receita líquida anual obtida com a exploração econômica, ressalvada a hipótese de redução para até 0,1 (um décimo) por acordo setorial previsto no art. 21.

Art. 21. Com o fim de garantir a competitividade do setor contemplado, a União poderá, a pedido do interessado, conforme o regulamento, celebrar acordo setorial que permita reduzir o valor da repartição de benefícios monetária para até $0,1 \%$ (um décimo por cento) da receita líquida anual obtida com a exploração econômica do produto acabado ou do material reprodutivo oriundo de acesso ao patrimônio genético ou ao conhecimento tradicional associado de origem não identificável” (BRASIL, 2015).

${ }^{7}$ Domínio público é o conjunto de todos os bens públicos corpóreos ou incorpóreos, imóveis, móveis, créditos, direitos e ações. Ou seja, todos os bens que pertecem às pessoas jurídicas de Direito Público (União, Estados, Distrito Federal e Municípios, fundações e autarquias), bem como os que, embora não pertencentes a tais pessoas, estejam afetados à prestação de um serviço público. E a afetação do bem à satisfação da necessidade coletiva impede a aplicação do regime de direito privado comum (BITTENCOURT, 2015, p. 205).
} 
e informado aos órgãos competentes, entre outras hermenêuticas" (RIBEIRO; BRITO, 2017, p. 14).

Assim, o "consentimento livre, prévio informado" é exigido apenas em relação aos CTAs de origem identificável eis que quanto aos saberes de origem nãoindentificável, não o é exigido, o que provoca, obviamente, um descontrole dos acontecimentos por parte dessas comunidades e uma propensão ao manejo de informações de origem por parte de pessoas físicas ou jurídicas que, conforme supracitado poderão argumentar óbice na delimitação da procedência daquele conhecimento.

É o que ocorre, por exemplo, no caso dos conhecimentos tradicionais associados (CTAs) sobre as propriedades medicinais de uma planta, onde a distinção entre CTAs identificáveis e não identificáveis é deveras complexa. Complexa porque normalmente o conhecimento é partilhado por várias populações indígenas, comunidades tradicionais e vendedores de ervas medicinais. Sob este aspecto, destaca Brito e Pozzetti que "o próprio usuário pode alegar que não é possível identificar a origem desse conhecimento" (COSTA, 2017, p. 47).

Aliás, recentemente, uma pesquisa no médio Rio Negro, localizado na Região Amazônica, evidenciou que a população do Município de Barcelos é detentora de um extenso conhecimento sobre o uso de plantas medicinais antimaláricas:

O conhecimento do uso de plantas antimaláricas é bem desenvolvido em comunidades do município de Barcelos, no médio rio Negro, onde a incidência de malária ainda é alta. Relatamos 55 plantas usadas para tratar a infecção por malária, entre elas 16 espécies que não haviam sido mencionadas anteriormente em outras publicações como antimaláricos. Especialistas locais citaram mais plantas antimaláricas do que homens e citaram mais plantas relacionadas a ambientes domésticos, enquanto os homens citaram mais espécies de plantas encontradas nas florestas vizinhas. A maioria das plantas antimaláricas usadas pelas pessoas locais tinham gosto amargo. $O$ uso exclusivo de plantas para o tratamento da malária tende a ser maior quando os provedores de saúde convencionais estão ausentes. Outros fatores podem estar envolvidos com o uso de plantas antimaláricas, mas devem ser mais estudados, como a acessibilidade dessas plantas e sua eficiência e segurança. Das 55 espécies relatadas, apenas 25 foram caracterizadas através de ensaios biológicos, o que destaca a importância da pesquisa etnobotânica para a identificação de novas drogas antimaláricas em potencial. ${ }^{8}$ (Tradução livre)

\footnotetext{
${ }^{8}$ The knowledge of the use of antimalarial plants is well developed in communities of the Barcelos municipality at the middle Negro River, where the incidence of malaria is still high. We report 55 plants used to treat malaria
} 
Nessa pesquisa etnobotânica ${ }^{9}$, todas as espécimes coletadas foram depositadas em herbário para estudo. Frise-se que, "dos 55 exemplares de plantas utilizadas para tratar a infecção por malária naquela região, 16 nunca foram citadas em outros trabalhos previamente publicados"(TOMCHINSKY; et. al., 2017). Significa dizer que pelo menos 16 plantas poderiam ser exploradas por grandes empresas, sem a justa repartição de benefícios e sem o respeito aos usos e costumes das populações nas quais há a incidência de tais plantas, pelo simples fato de as mesmas não terem sido previamente identificadas. Tudo sob a alegação de impossibilidade em dizer qual a origem daquele conhecimento.

É irrefutável o fato de que os conhecimentos tradicionais associados (CTAs) são muito importantes para a bioprospecção, com eles "as empresas reduzem em muito o tempo de pesquisa, de coleta de plantas, de isolamento de propriedades, de resultados e, consequentemente, o tempo de conversão da pesquisa em lucros. $O$ custo-benefício é baixíssimo" (MESSIAS, 2008, p. 78).

É por isso que "gigantes empresariais financiam expedições por todo o Hemisfério Sul, em busca de traços genéticos raros e originais que possam ter algum valor comercial" (BOFF, 2015, p. 115) É por isso que grandes empresas de biotecnologia apropriam-se de conhecimentos das populações tradicionais para, após, a elevados preços e "sob uma forma levemente alterada e patenteada" apresentar ao mercado "os mesmos produtos que foram livremente partilhados e comercializados entre agricultores e camponeses por toda a história da humanidade" (BOFF, 2015, p. 115).

infection, among them 16 species that had not been previously mentioned in other publications as antimalarial. Local women specialists cited more antimalarial plants than men, and cited more plants related to domestic environments, while men cited more plant species found in surrounding forests. Most antimalarial plants used by local people were bitter tasting. The exclusive use of plants for malaria treatment tends to be higher where conventional health providers are absent. Other factors could be involved with the use of antimalarial plants, but must be more studied, such as the accessibility of these plants and their efficiency and safety. Of the 55 reported species, only 25 have been characterized through biological essays, which highlights the importance of ethno botanical research for the identification of potential novel antimalarial drugs (TOMCHINSKY; et. al., 2017).

9 "A etnobotânica pode ser definida como o estudo da relação existente entre o Homem e as Plantas e o modo como essas plantas são usadas como recursos" (ROCHA; BOSCOLO; FERNANDES, 2015, p. 67). 
Nesse passo, a classificação inédita sugerida pela Lei da Biodiversidade é contraditória na medida em que, por um lado procura proteger o direito à cultura, ao meio ambiente ecologicamente equilibrado, ao patrimônio genético e à biodiversidade do país e, por outro, abre passagens para que grandes indústrias - em especial do ramo da farmacologia e da estética - usurpem os conhecimentos tradicionais das populações tradicionais sem preocupações de salvaguarda dos CTAs, nem tampouco de qualquer sorte de distribuição de benefícios com tais populações (BARBA, 2017, p. 19).

Ainda, em relação à repartição de benefícios dos CTAs não indentificáveis, a nova Lei da Biodiversidade dispõe que o usuário pode explorar comercialmente o produto pronto pelo período de 365 dias e não resolver a questão da partilha com a União ou com o Fundo Nacional para Repartição de Benefícios (FNRB) - conforme preceitua o artigo 16, $\S^{\circ}$ (BRASIL, 2015) ${ }^{10}$. Ora, "qual o bem/interesse que esse dispositivo pretendeu proteger?" (SANTILLI, sem data, p. 47). A Convenção sobre a Diversidade Biológica (CDB), ratificada pelo Brasil, prevê a repartição justa e equitativa dos benefícios derivados da utilização dos CTAs já em seu preâmbulo:

"Reconhecendo a estreita e tradicional dependência de recursos biológicos de, muitas comunidades locais e populações indígenas com estilos de vida tradicionais, e que é desejável repartir equitativamente os benefícios derivados da utilização do conhecimento tradicional, de inovações e de práticas relevantes à conservação da diversidade biológica e à utilização sustentável de seus componentes" (BRASIL, 1998).

Assim, entende-se que é manifesto 0 desajuste entre normas infraconstitucionais e normas internacionais ratificadas pelo país - tratando-se do controle de convencionalidade -, bem como o descompasso com os preceitos constitucionais $^{11}$ - sob a análise do controle de constitucionalidade.

\footnotetext{
10 "Art. 16. Para a exploração econômica de produto acabado ou material reprodutivo oriundo de acesso ao patrimônio genético ou ao conhecimento tradicional associado serão exigidas: (...) §2으 $\mathrm{O}$ acordo de repartição de benefícios deve ser apresentado em até 365 (trezentos e sessenta e cinco) dias a partir do momento da notificação do produto acabado ou do material reprodutivo, na forma prevista no Capítulo $\mathrm{V}$ desta Lei, ressalvados os casos que envolverem conhecimentos tradicionais associados de origem identificável". (BRASIL, 2015).

11 “Art. 225. Todos têm direito ao meio ambiente ecologicamente equilibrado, bem de uso comum do povo e essencial à sadia qualidade de vida, impondo-se ao Poder Público e à coletividade o dever de defendê-lo e preservá-lo para as presentes e futuras gerações: II - preservar a diversidade e a integridade do patrimônio
} 
Infelizmente sob o aspecto participativo dos povos indígenas, das comunidades tradicionais e dos agricultores tradicionais, pode-se dizer que a Lei da Biodiversidade também deixou a desejar. Isso porque, houve um déficit democrático enorme na própria construção da norma. Foram poucas as comunidades ou representantes dos interesses dessas comunidades que participaram efetivamente desse processo. A norma foi elaborada em sua maioria sob a ótica do setor empresarial, o que confere, obviamente, insegurança quanto ao seu conteúdo ${ }^{12}$.

Dessa forma, diante da situação de vácuo legislativo e da incongruência entre diplomas jurídico-normativos ratificados pelo país, bem como tendo em conta a insuficiência fiscalizatória, a atual situação dos povos e comunidades tradicionais é agravada sobremaneira, devido ao uso indiscriminado de seus saberes associados, sendo a eles relegado o mero papel de espectadores do desenvolvimento sobejo que em nada os beneficia. O desafio, portanto, é uma maior participação das populações tradicionais na elaboração das normas em geral, de planos e programas de governo para que as políticas de comando e controle do Estado sejam inclusivas e efetivas.

\section{3) A NECESSIDADE DA CONSTRUÇÃO DE UM SISTEMA SUI GENERIS PARA A PROTEÇĀO DOS CONHECIMENTOS ASSOCIADOS AOS POVOS E COMUNIDADES TRADICIONAIS}

Em que pese a aparente proteção da Lei da Biodiversidade (BRASIL, 2015) aos direitos dos povos indígenas, às comunidades tradicionais e aos agricultores tradicionais, é visível que tais normas estão distantes de ser consideradas satisfatórias e eficazes. Por isso renomados autores vêm acenando para a necessidade da instituição de um Sistema Sui Generis de proteção desses saberes.

genético do País e fiscalizar as entidades dedicadas à pesquisa e manipulação de material genético; § 2ㅇ Aquele que explorar recursos minerais fica obrigado a recuperar o meio ambiente degradado, de acordo com solução técnica exigida pelo órgão público competente, na forma da lei. § 4ㅇ A Floresta Amazônica brasileira, a Mata Atlântica, a Serra do Mar, o Pantanal Mato-Grossense e a Zona Costeira são patrimônio nacional, e sua utilização far-se-á, na forma da lei, dentro de condições que assegurem a preservação do meio ambiente, inclusive quanto ao uso dos recursos naturais". CONSTITUIÇÃO FEDERAL BRASILEIRA 1988. Disponível em: < http://www.planalto.gov.br/ccivil 03/constituicao/constituicao.htm>. 
A título de exemplo, Vandana Shiva argumenta que o que falta é a aplicação, o respeito ao "princípio do direito soberano das comunidades locais que conservaram e preservaram a biodiversidade e cuja sobrevivência cultural está intimamente ligada à sobrevivência da biodiversidade, à conservação e uso da diversidade biológica" (SHIVA apud SEGALLA; DE GREGORI, 2016, p. 211). Isso porque, de acordo com Juliana Santilli:

(...) Os mecanismos mais eficientes e equitativos de repartição de benefícios são aqueles que implicam a participação e o envolvimento das comunidades nas atividades de pesquisa e desenvolvimento, sua capacitação e treinamento para uma participação efetiva e qualificada e não apenas formal, o acesso a tecnologias, inclusive biotecnologias protegidas por patentes e outros direitos de propriedade intelectual, e a participação nos lucros auferidos com a comercialização de produtos (SANTILLI, sem data).

Desta feita, para tentar solucionar os problemas elencados anteriormente, propõe-se um sistema que se fundamenta na abertura do processo decisório, que procure um equilíbrio entre economia e meio ambiente, que não tenha um viés predominantemente mercadológico, que contribua de fato para que a minoria não seja apenas consultada, mas que também tenha voz na construção da proteção dos conhecimentos e saberes dos seus povos e comunidades tradicionais. Em linhas gerais, um sistema que de fato observe o direito ao "consentimento livre, prévio e informado" (SEGALLA; DE GREGORI, 2016, p. 212).

Assim, Márcia Kesseler, ao citar Nijar sugere alguns aspectos que devem ser considerados quando da construção de um novos Sistema Sui Generis para a proteção dos conhecimentos associados aos povos e comunidades tradicionais:

a) admissão de uma definição alternativa de sistemas de conhecimento (capaz de entender o sistema de inovação informal, coletivo e cumulativo dos povos indígenas e comunidades locais); b) redefinição do termo "inovação", de forma a ser ampla o suficiente para abarcar o conhecimento relativo ao uso de propriedades, valores e processos de qualquer recurso biológico; c) transformação dos povos indígenas e comunidades locais em "guardiães" das inovações, definindo esses direitos como "não exclusivos", mediante incentivo ao intercâmbio livre e sem fins comerciais; d) manutenção dos direitos em comum com outros povos indígenas e comunidades locais (KESSLER, 2015, p. 16). 
Destaca-se a importância da criação de um novo Sistema "Sui Generis" com o intento de tutelar os conhecimentos associados aos povos e comunidades tradicionais pois 0 atual sistema como está desenhado "negligencia a proteção da variabilidade dos recursos genéticos e também dos conhecimentos tradicionais associados" (GALLI APRÁ; DE LARA, 2017, p. 158).

A emergência desse regime jurídico diferenciado pressupõe uma mudança de hermenêutica que só será vantajosa quando o Estado, as empresas e a sociedade civil se perceberem como parte de um todo igualitário. Tal mudança de pensamento deve se dar no sentido de entrelaçamento, interdependência de todos os fenômenos, onde nenhuma parte se sobreponha às demais. Enquanto prevalecerem os jogos de interesses, a proteção das minorias provavelmente será aparente (CAPRA, 2006, p. 4849). Ou melhor, qualquer proteção sobre qualquer bem ou direito será aparente.

A legislação não pode ser "uma obra prima de ambiguidades" (COSTA, 2017, p. 80), deve ser coerente tanto em relação ao seu conteúdo quanto em relação ao conteúdo de outros diplomas normativos, sob pena de estremecer ainda mais a relação sociedade-Estado, leia-se: sociedade-Estado-empresas. Dessa forma, no atual estágio de desenvolvimento, enquanto não houver uma alfabetização ecológica e cultural, tão pouco haverá consciência na participação na tomada de decisões e, consequentemente, na efetividade da tutela dos CTAs - leia-se também: dos diretos humanos.

\section{2) CONSIDERAÇÕES FINAIS}

O presente estudo buscou evidenciar que os principais problemas relacionados aos conhecimentos tradicionais associados (CTAs) transcendem marcos territoriais das localidades nas quais estão inseridas as Populações Tradicionais e acabam por atingir toda a sociedade brasileira direta ou indiretamente na medida em que atingem os direitos humanos dessas pessoas. Por isso se faz necessário o balizamento de 
quaisquer medidas que se prestem a solucionais tais problemas calcadas em princípios que direcionem as condutas humanas.

Aliás, procurou-se demonstrar que, em que pese haver inúmeras normas acerca do tema, as políticas públicas e as próprias normas estão distantes de ser consideradas satisfatórias e eficazes. Considerando-se que os conhecimentos tradicionais associados (CTAs) não escapam aos interesses políticos, científicos e aqueles oriundos do capitalismo, as Populações Tradicionais - que conformam o elo mais frágil das inter-relações que envolvem tais atores - precisam ser protegidas.

Espera-se ter logrado êxito em demonstrar que há completa inter-relação entre economia, cultura e natureza, e que países em desenvolvimento como o Brasil se encontram diante da oportunidade de, além de priorizar o desenvolvimento, acoplá-lo ao respeito ao meio ambiente e à cultura dos Povos e Comunidades Tradicionais muitos dos quais são originários, os verdadeiros brasileiros que aqui já se encontravam antes mesmo da colonização e que, ao longo da história, foram e continuam sendo explorados, situação que não deve se perpetuar.

Ao destacar o vácuo legislativo no que tange à definição exata de uma nomenclatura formal acerca do princípio do "consentimento livre, prévio e informado" destacou-se que tal princípio se presta a ser um balizamento em relação aos direitos fundamentais dos Povos e Populações Tradicionais e uma espécie de garantia de efetividade dos demais direitos a eles reconhecidos no que se refere aos direitos humanos, em todas as esferas de atuação, ou seja, no local ou regional e também no plano nacional e até mesmo em âmbito global.

As incongruências normativas no plano nacional e também em relação às normas internacionais ratificadas pelo Brasil e, ainda, a precária fiscalização do uso que se faz dos Conhecimentos Tradicionais Associados (CTAs) - inclusive devido ao sucateamentos dos órgãos ambientais e daqueles que deveriam exercer o poder de comando e de controle do Estado - acabam por privilegiar apenas aqueles que aviltam os Povos e Populações Tradicionais, as quais se veem como meras expectadoras do dilapidamento do patrimônio ambiental que integra os seus territórios disfarçado de "desenvolvimento". 
Diante desta realidade, acredita-se que um Sistema Jurídico "Sui Generis" deve se desenvolver fundamentado em processos decisórios participativos; precisa levar em real consideração o respeito ao equilíbrio entre valores econômicos e ecossistêmicos e não priorize apenas uma visão meramente mercantilista imediatista; e impõe que se considere realmente o protagonismo dos Povos e Comunidades Tradicionais em relação aos usos que se faz dos seus saberes e conhecimentos associados, tomando em conta a observância do seu direito ao "consentimento livre, prévio e informado".

Tal Sistema Jurídico "Sui Generis" pode ser a solução para os desafios relativos à proteção dos direitos intelectuais coletivos associados aos Povos e Comunidades Tradicionais Brasileiros, sendo que a participação de toda a sociedade brasileira pode auxiliar na sua construção, concretizando, assim, a incumbência constitucional de todos lutarem pelo meio ambiente ecologicamente equilibrado, indispensável para a sadia qualidade de vida das presentes e futuras gerações!

\section{REFERÊNCIAS}

BARBA, Romina Ysabel Bazán. Diversidade biológica e dos saberes: Lei da Biodiversidade e Protocolo de Nagoya. Dissertação apresentada ao Programa de Pós-Graduação em Direito Agrário da Universidade Federal de Goiás -UFG, para obtenção do grau de Mestre em Direito, Goiânia, 2017. Disponível em: https://repositorio.bc.ufg.br/tede/bitstream/tede/7179/5/Disserta\%c3\%a7\%c3\%a30\%20\%20Romina\%20Ysabel\%20Baz\%c3\%a1n\%20Barba\%20-\%202017.pdf. Acesso em: 26 mai. de 2019.

BIJOS, Leila; HESSEL; Carmem Elisa. Sistema Interamericano de Direitos Humanos: proteção ao meio ambiente. Revista de Direitos Humanos em Perspectiva. Curitiba: v. 2, n.ำ 2, p. 78-98. Jul/Dez, 2016.

BOFF, Salete Oro. Acesso aos conhecimentos tradicionais: repartição de benefícios pelo "novo" marco regulatório. Revista Direito Ambiental e sociedade, v. 5, $\quad$ n. 2015.20 Disponível <http://www.ucs.br/etc/revistas/index.php/direitoambiental/article/view/3951>.

BRASIL. Constituição da República Federativa do Brasil de 1988. Disponível em: <http://www.planalto.gov.br/ccivil_03/constituicao/constituicaocompilado.htm>. Acesso em 09 abr. 2019. 
. Decreto n. 592, de 6 de julho de 1992. Atos Internacionais. Pacto Internacional sobre Direitos Civis e Políticos. Promulgação. Disponível em: $<$ http://www.planalto.gov.br/ccivil 03/decreto/1990-1994/d0592.htm>. Acesso em 09 abr. 2019.

. Decreto n.o 2.519, de 16 de março de 1998. Promulga a Convenção sobre Diversidade Biológica, assinada no Rio de Janeiro, em 05 de junho de 1992. Disponível em <http://www.mma.gov.br/estruturas/sbf_dpg/_arquivos/cdbport.pdf >. Acesso em 03 abr. 2019.

.. Lei n. 11.105, de 24 de março de 2005. Regulamenta os incisos II, IV e V do $\S 1^{\circ}$ do art. 225 da Constituição Federal, estabelece normas de segurança e mecanismos de fiscalização de atividades que envolvam organismos geneticamente modificados - OGM e seus derivados, cria o Conselho Nacional de Biossegurança CNBS, reestrutura a Comissão Técnica Nacional de Biossegurança - CTNBio, dispõe sobre a Política Nacional de Biossegurança - PNB, revoga a Lei no 8.974, de 5 de janeiro de 1995, e a Medida Provisória no 2.191 - 9, de 23 de agosto de 2001, e os arts. $5^{\circ}, 6^{\circ}, 7^{\circ}, 8^{\circ}, 9^{\circ}, 10$ e 16 da Lei no 10.814, de 15 de dezembro de 2003, e dá outras providências. Disponível em: <http://www.planalto.gov.br/ccivil_03/_Ato20042006/2005/lei/L11105.htm>. Acesso em 01 abr. 2019.

. Decreto n. .6 .040 , de 07 de fevereiro de 2007. Institui a Política Nacional de Desenvolvimento Sustentável dos Povos e Comunidades Tradicionais. Disponível em: <http://www.planalto.gov.br/ccivil 03/ Ato2007-2010/2007/Decreto/D6040.htm>. Acesso em 01 abr. 2019.

. Lei $\mathrm{n} . \mathrm{o}$ 13.123, de 20 de maio de 2015. Regulamenta o inciso II do $\S 1^{\circ}$ e o $\S$

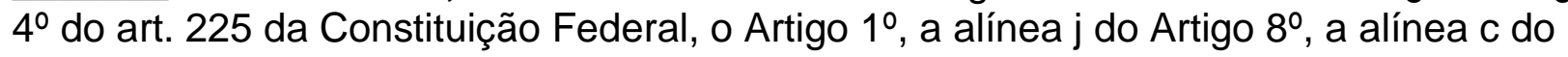
Artigo 10, o Artigo 15 e os $\S \S 3^{\circ}$ e 4ํำ do Artigo 16 da Convenção sobre Diversidade Biológica, promulgada pelo Decreto n.. 2.519, de 16 de março de 1998; dispõe sobre o acesso ao patrimônio genético, sobre a proteção e o acesso ao conhecimento tradicional associado e sobre a repartição de benefícios para conservação e uso sustentável da biodiversidade; revoga a Medida Provisória n.ำ 2.186-16, de 23 de agosto de 2001; e dá outras providências. Disponível em:

<http://www.planalto.gov.br/ccivil_03/_Ato2015-2018/2015/Lei/L13123.htm>. Acesso em 01 abr. 2019.

CAPRA, Fritjof. A teia da vida: uma nova compreensão científica dos sistemas vivos. São Paulo: Cultrix, 2006.

COSTA, Catharyna Silva. A proteção da biodiversidade e dos conhecimentos tradicionais associados em face dos direitos de propriedade intelectual. 2017. Dissertação (Graduação em Direito) - Universidade do Estado do Amazonas, UEA, Manaus. Disponível em:

<http://repositorioinstitucional.uea.edu.br/bitstream/riuea/936/1/A\%20prote\%c3\%a7\%c3

\%a30\%20da\%20biodiversidade\%20e\%20dos\%20conhecimentos\%20tradicionais\%20as 
sociados\%20em\%20face\%20aos\%20direitos\%20de\%20propriedade\%20intelectual.pdf >. Acesso em 19 abr. 2019.

DERANI, Cristiane. Patrimônio genético e conhecimento tradicional associado: considerações jurídicas sobre seu acesso. In, LIMA, André. (org.). 0 direito para 0 Brasil socioambiental. Porto Alegre: Sérgio Antônio Fabris Editor, 2002, apud

DANTAS, Fernando Antônio de Carvalho. Base jurídica para a proteção dos conhecimentos tradicionais. Revista CPC, São Paulo, v.1, n.2, p.80-95, maio/out. 2006, p. 84. Disponível em <http://www.usp.br/cpc/v1/imagem/conteudo_revista_conservacao_arquivo_pdf/fernand o_dantas.pdf>. Acesso em 03 abr. 2019.

\section{DECLARAÇÃO DAS NAÇÕES UNIDAS SOBRE OS DIREITOS DOS POVOS} INDíGENAS. Publicada em: Rio de Janeiro, mar. 2008. Disponível em: $<$ http://www.un.org/esa/socdev/unpfii/documents/DRIPS_pt.pdf>. Acesso em $10 \mathrm{abr}$. 2019.

Dicionário Priberam da Língua Portuguesa [em linha], 2008-2013, Disponível em: $<$ https://dicionario.priberam.org/biopirataria [consultado em 05-04-2019]>. Acesso em 05 abr. 2019.

GALLI APRÁ, Alessandra; DE LARA, Beatriz Cobbo. Ensaio sobre meio ambiente e organismos Geneticamente Modificados (OGMs) no Brasil. Revista de Direitos Difusos Volume 67, Janeiro-Junho, Ano XVII. Editora Letras Jurídicas: São Paulo, páginas 136-166, 2017.

GRABNER, Maria Luiza. O direito humano ao consetimento livre, prévio e informado como baluarte do sistema jurídica de proteção dos conhecimentos tradicionais. Boletim Científico ESMPU, Brasília, a. 14 - n. 45 - jul./dez. 2015. Disponível em: <http://www.mpf.mp.br/atuacao-tematica/ccr6/documentos-epublicacoes/artigos/docs artigos/1-o-direito-humano-ao-consentimento-livre-previo-einformado-1.pdf>. Acesso em: 05 abr. 2019.

KESSLER, Márcia Samuel. Biotecnologia e conhecimentos tradicionais ambientais: um diálogo necessário na promoção de direitos fundamentais. Disponível em: https://webcache.googleusercontent.com/search?q=cache:XwMbrpb13RkJ:https://dialne t.unirioja.es/descarga/articulo/5460328.pdf $+\& \mathrm{~cd}=1 \& \mathrm{hl}=\mathrm{pt}-\mathrm{PT} \& \mathrm{ct}=\mathrm{clnk} \& \mathrm{gl}=\mathrm{br}$. Publicado em 01 abr. 2015. Acesso em 27 de maio de 2019.

MAGALHÃES, Vladimir Garcia. Propriedade Intelectual: biodiversidade e biotecnologia. São Paulo: Editora Fuiza, 2011.

MESSIAS, Marcos Perez; LEITE, Werley Barbosa. Bioprospecção dos recursos genéticos dos conhecimentos tradicionais associados no Brasil: autorização ou liceça administrativa? Revista de Direito e Política. Volume 16 - jan-abril - 2008 - Ano V. São Paulo: Letras Jurídicas. 
RIBEIRO, Luiz Gustavo Gonçalves; BRITO, Natália Bastos do Vale. Participação das comunidades tradicionais na lei de acesso aos recursos genéticos: diálogos com a teoria discursiva do direito em Habernas. Revista dos Tribunais. v. 87/2017, jul-set. 2017.

ROCHA, Joyce Alves; BOSCOLO, Odara Horta; FERNANDES, Lucia Regina Rangel de Moraes Valente. Etnobotânica: um instrumento para valorização e identificação de potenciais de proteção do conhecimento tradicional. In INTERAÇÕES, Campo Grande, v. 16, n. 1, p. 67-74, jan./jun. 2015.

SANTILLI, Juliana. Conhecimentos Tradicionais Associados à Biodiversidade: Elementos Para A Construção De Um Regime Jurídico Sui Generis de Proteção. Sem data. Disponível em: <http://www.anppas.org.br/encontro_anual/encontro2/GT/GT08/juliana_santilli.pdf>.

SANTOS, Boaventura de Sousa; NUNES, João Arriscado. Reconhecer para libertar: os caminhos do cosmopolitismo multicultural/ Boaventura de Sousa Santos, organizador. - Rio de Janeiro: Civilização Brasileira, 2003. Disponível em: < https://www.ces.uc.pt/publicacoes/res/pdfs/IntrodMultiPort.pdf> Acesso em 27 de maio de 2019.

SEGALA, Mado; DE GREGORI, Isabel Christine Silva. A construção de uma justiça socioambiental por meio da instituição de um sistema sui generis de proteção dos conhecimentos tradicionais associados. Revista de Direito, Inovação, Propriedade Intelectual e Concorrência. V. 2, n. 1, 2016, p. 212. Disponível em: < https://indexlaw.org/index.php/revistadipic/article/view/940>. Acesso em: 15 de maio de 2019.

TOMCHINSKY, Bernardo; MING, Lin Chau; KINUPP, Valdely Ferreira; HIDALGO, Ari de Freitas; CHAVES, Francisco Célio Maia. Ethnobotanical study of antimalarial plants in the middle region of the Negro River, Amazonas, Brazil. Acta Amaz. vol. 47 №.3 Manaus July/Sept. $2017 . \quad$ Disponível em: <http://www.scielo.br/scielo.php?script=sci_arttext\&pid=S0044$59672017000300203 \&$ lang=pt>. Acesso em: 17 de abril de 2019. 